\title{
GERMINAÇÃO DE SEMENTES DE TANCHAGEM (Plantago tomentosa Lam.): INFLUÊNCIA DA TEMPERATURA, LUZ E SUBSTRATO
}

\author{
Germination of Plantago tomentosa Lam. seeds: influence of the temperature, \\ light and substrate
}

\author{
Sara Dousseau ${ }^{1}$, Amauri Alves de Alvarenga² ${ }^{2}$ Lúcio de Oliveira Arantes ${ }^{1}$, Davi Melo de Oliveira ${ }^{3}$, \\ Fernanda Carlota Nery ${ }^{4}$
}

\begin{abstract}
RESUMO
Plantago tomentosa Lam. (Plantaginaceae) é usada na medicina popular como agente anti-tumoral, antimicrobiana e antinflamatória. Sua propagação ocorre por meio de sementes, cuja germinação tem sido pouco investigada. Dessa forma, o presente trabalho teve como objetivo verificar a influência da luz, temperaturas e substratos sobre a porcentagem total de germinação/ emergência e índice de velocidade de germinação/emergência. Foram testadas diferentes temperaturas $\left(15,20,25,30\right.$ e $35^{\circ} \mathrm{C}$ constantes e, $15-25^{\circ} \mathrm{C}$ e $20-30^{\circ} \mathrm{C}$ alternadas) na ausência e presença de luz constante. Os substratos testados foram areia, terra de subsolo, vermiculita e Plantmax ${ }^{\circledast}$, além da combinação de terra de subsolo com os demais, na proporção de 1:1. Pelos resultados obtidos, concluiu-se que as sementes de tanchagem apresentam comportamento fotoblástico positivo, independente da temperatura testada. A temperatura alternada de $15-25^{\circ} \mathrm{C}$ e 15 e $20^{\circ} \mathrm{C}$ constantes garantem melhor expressão do vigor. $\mathrm{O}$ substrato areia é recomendado para o estudo da emergência.
\end{abstract}

Termos para indexação: Planta medicinal, propagação sexuada, dormência, fotoblastismo.

\begin{abstract}
Plantago tomentosa Lam. (Plantaginaceae) is used in the popular medicine as anti-tumoral, antimicrobial and anti-inflammatory agent. This propagation is basically done by seeds, which the publications available are scarce. The objective of this research was to study the influence of the light, temperatures and substrate on the total percentage of germination/emergency and index of germination/ emergency speed. There were used different temperatures $\left(15,20,25,30\right.$ and $35^{\circ} \mathrm{C}$ constant and, $15-25^{\circ} \mathrm{C}$ and $20-30^{\circ} \mathrm{C}$ alternated) in the absence and presence of constant light. The substrate tested were subsoil sand, land, vermiculite and Plantmax ${ }^{\circledR}$, besides the subsoil land combination, in the ratio of 1:1. the results suggest that Plantago tomentosa seeds was a positive photoblastic behavior, independent of the tested temperature. The use of constant temperature of 15 and $20^{\circ} \mathrm{C}$ and alternated $\left(15-25^{\circ} \mathrm{C}\right)$ promated a higher vigor expression. The substrate sand is recommended for the emergency study.
\end{abstract}

Index terms: Medicinal plant, sexual propagation, dormancy, photoblastic.

(Recebido em 27 de abril de 2006 e aprovado em 13 de dezembro de 2006)

\section{INTRODUÇÃO}

Plantago tomentosa Lam. (Plantaginaceae), popularmente conhecida como tanchagem é nativa da Europa e, no Brasil, é encontrada na região Sul e CentroOeste (KISSMANN \& GROTH, 2000). Na medicina popular é usada no tratamento das inflamações bucofaringeanas, dérmicas, gastrintestinais e das vias urinárias e seu extrato metanólico usado no tratamento de câncer (HARTWELL, 1982; MARTINS et al., 2000; UPNMOOR, 2003).

Segundo Duarte et al. (2002), o extrato da planta inteira, obtido tanto por decocção como por infusão, apresenta atividade comprovada contra Bactéria Grampositiva (Staphylococcus aureus) e Bactérias Gram- negativas (Escherichia coli, Salmonella typhimurium e Pseudomonas aeruginosa).

Segundo Babbar \& Jain (1998), a mucilagem proveniente das sementes do gênero plantago, pode ser empregada como agente solidificante em meios de cultura, em substituição ao ágar proveniente de algas vermelhas.

Apesar de ser uma espécie de elevado potencial econômico e amplamente utilizada na medicina popular, há uma carência generalizada de informações no que diz respeito à fisiologia da germinação de suas sementes. O conhecimento das condições ideais para a germinação da semente de uma determinada espécie é de fundamental importância, principalmente, pelas respostas diferenciadas

\footnotetext{
${ }^{1}$ Mestranda(o) - Departamento de Biologia/DBI - Universidade Federal de Lavras/UFLA - Cx. P. 3037 - $37.200-000$ - Lavras, MG saradousseau@yahoo.com.br; lucio arantes@yahoo.com.br

${ }^{2}$ Doutor, Professor Titular - Departamento de Biologia/DBI - Universidade Federal de Lavras/UFLA - Cx. P. 3037 - $37.200-000$ - Lavras, MG amauriaa@uflanet.br

3Mestrando em Fitotecnia - Departamento de Fitotecnia - Universidade Federal de Viçosa/UFV - 36570-000 - Viçosa, MG - dmo.agro@yahoo.com.br ${ }^{4}$ Doutoranda em Agronomia/Fisiologia Vegetal - Departamento de Biologia/DBI - Universidade Federal de Lavras/UFLA - Cx. P. 3037 - $37200-000$ -

Lavras, MG - fernandacarlota@yahoo.com.br
} 
que ela pode apresentar em função de diversos fatores, como viabilidade, dormência, condições de ambiente, envolvendo água, luz, temperatura, oxigênio e ausência de agentes patogênicos, associados ao tipo de substrato para sua germinação (BEWLEY \& BLACK, 1994; BRASIL, 1992; CARVALHO \& NAKAGAWA, 2000).

Dentre os diversos fatores do ambiente físico, a temperatura tem sido considerada como um dos principais responsáveis tanto pela porcentagem final de germinação como pelo índice de velocidade (IVG), por afetar especialmente a velocidade de absorção de água, e a reativação das reações metabólicas, fundamentais aos processos de mobilização de reservas e a retomada de crescimento da radícula (BEWLEY \& BLACK, 1994).

O substrato também apresenta grande influência na germinação/emergência, pois fatores como aeração, estrutura, capacidade de retenção de água, grau de infestação de patógenos, entre outros, podem variar de um substrato para outro, favorecendo ou prejudicando a germinação das sementes (POPININGIS, 1985). Na escolha do substrato, deve ser levado em consideração o tamanho da semente, sua exigência em relação à umidade e sensibilidade ou não à luz (FIGLIOLIA et al., 1993).

Outro fator que vem sendo amplamente estudado é a luz, a qual exerce grande influência na germinação, sendo o embrião responsável pela percepção e tradução do estímulo luminoso (KOLLER, 1972). Segundo Bewley \& Black (1994), a sensibilidade das sementes à luz varia em função da espécie, da temperatura e do tamanho das sementes. Em geral, a luz é geralmente necessária para a germinação de sementes pequenas, denominadas fotoblásticas positiva (ABREU \& GARCIA, 2005; BEWLEY \& BLACK, 1994), cujas espécies estão associadas a ambientes abertos (OLIVEIRA \& GARCIA, 2005) ou perturbados (ACOSTA-PERCÁSTEGUI \& RODRÍGUEZTREJO 2005).

Diante do exposto, o presente trabalho teve como objetivo verificar a influência da temperatura, luz e substrato sobre o comportamento germinativo das sementes de Plantago tomentosa Lam.

\section{MATERIAL E MÉTODOS}

Os experimentos foram conduzidos no Laboratório de Crescimento e Desenvolvimento de Plantas do Departamento de Biologia da Universidade Federal de Lavras (UFLA), em Lavras-MG. Os frutos foram coletados de plantas localizadas no campus da UFLA e conduzidas ao laboratório para beneficiamento.
Em todos os experimentos, a análise estatística foi realizada mediante o uso do programa estatístico SISVAR (FERREIRA, 1999). Os dados de germinação/emergência foram transformados em arco seno $(\mathrm{x} / 100)^{0,5}$ e o índice de velocidade de germinação/emergência em $(\mathrm{x}+0,5)^{0,5}$ (BARTLETT, 1936; ZAR, 1999). Foi realizada a análise de variância e as médias foram comparadas pelo teste de Tukey (1949), a 5\% de probabilidade.

Utilizou-se o delineamento inteiramente casualizado com 4 repetições de 100 sementes/gerbox. Avaliações diárias determinaram à porcentagem de germinação $(\% \mathrm{G})$ e de emergência (\%E), sendo o critério, respectivamente, a protrusão da radícula e a elevação das plântulas na superfície do substrato. O índice de velocidade de germinação (IVG) e de emergência (IVE) foi calculado segundo Maguire (1962).

\section{Efeitos da temperatura e luz}

Foram testadas diferentes temperaturas na ausência e presença de luz constante em ambiente com $100 \%$ de umidade relativa. As temperaturas constantes $\left(15^{\circ} \mathrm{C}, 20^{\circ} \mathrm{C}, 25^{\circ} \mathrm{C}, 30^{\circ} \mathrm{C}\right.$ e $\left.35^{\circ} \mathrm{C}\right)$ foram obtidas em câmara de germinação termogradiente. Enquanto as alternadas (15-25 -C e $20-30^{\circ} \mathrm{C}$ ) foram obtidas em câmara de germinação do tipo BOD.

As sementes foram distribuídas em caixas gerbox sob papel mata borrão perfurado e umedecido sempre que necessário. Para obter a ausência de luz, as caixas gerbox foram envoltas em papel alumínio e a avaliação feita em ambiente escuro, sob luz verde.

\section{Efeito do substrato}

Foram testados os substratos areia, terra de subsolo, vermiculita e Plantmax ${ }^{\circledR}$ e, a combinação de terra de subsolo com areia, vermiculita e Plantmax ${ }^{\circledR}$, na proporção de 1:1. A semeadura foi efetuada sobre o substrato, em caixa gerbox contendo $250 \mathrm{~mL}$ do mesmo, umedecido diariamente. $\mathrm{O}$ experimento foi conduzido em sala de crescimento, sob temperatura de $25 \pm 2^{\circ} \mathrm{C}$ e fotoperíodo de 12 horas.

\section{RESULTADOS E DISCUSSÃO}

\section{Efeitos da temperatura e da luz}

Independente das temperaturas testadas, não foi observada germinação no escuro, sendo a luz um fator essencial à germinação desta espécie. Resultados semelhantes, porém com espécies diferentes, foram encontrados por Oliveira \& Garcia (2005) em sementes de Syngonanthus elegantulus Ruhland e por Abreu \& Garcia (2005), trabalhando com Xyris cipoensis Smith \& Downs, 
X. longiscapa A. Nilsson, X. platystachia A. Nilsson e X. trachyphylla Mart..

Conforme se observa na Figura 1A, as temperaturas de $15^{\circ} \mathrm{C} 20^{\circ} \mathrm{C}, 25$ e $15-25^{\circ} \mathrm{C}$ promoveram porcentagens de germinação superior aos tratamentos térmicos de $35^{\circ} \mathrm{C}$, $30^{\circ} \mathrm{C}$ e $20-30^{\circ} \mathrm{C}$, sendo a temperatura de $35^{\circ} \mathrm{C}$, a que apresentou menor germinação.

Quanto ao IVG, os maiores valores foram encontrados a 15,20 e $15-25^{\circ} \mathrm{C}$. Temperatura constante de $25^{\circ} \mathrm{C}$ e alternada de $20-30^{\circ} \mathrm{C}$, conferiram o segundo maior IVG, enquanto o menor valor de IVG ocorreu a $35^{\circ} \mathrm{C}$, seguido de a $30^{\circ} \mathrm{C}$ (Figura $\left.1 \mathrm{~B}\right)$.

Para muitas espécies, baixas temperaturas podem não somente reduzir a porcentagem de germinação, como também retardar o processo, devido à redução das atividades enzimáticas envolvidas no metabolismo da semente (BEWLEY \& BLACK, 1994; OLIVEIRA et al., 2005). Entretanto, para a tanchagem temperaturas constantes de 15 e $20^{\circ} \mathrm{C}$ e alternada de $15-25$, promoveram maiores porcentagens de germinação e IVG.

Segundo Thompson (1970), a variabilidade de respostas quanto ao requerimento de temperatura é um reflexo da adaptação das espécies ao ambiente de ocorrência. Isto explica a maior germinação da tanchagem a temperaturas mais baixas, pois esta espécie é nativa da Europa e encontrada em regiões frias do Brasil (KISSMANN \& GROTH, 2000).

Por outro lado, sob temperaturas mais altas, a velocidade de absorção de água e as atividades enzimáticas tornam-se mais elevadas, fazendo com as sementes germinem mais rapidamente (CARVALHO \& NAKAGAWA, 2000; VARELA et al., 2005). Entretanto, podem ser prejudiciais à germinação de algumas espécies, provavelmente por causarem desnaturação de proteínas essenciais ao processo germinativo. Para a espécie em questão foi observada queda brusca na porcentagem de germinação e $\mathrm{IVG}$ a $35^{\circ} \mathrm{C}$.

Resultados semelhantes foram obtidos por Abreu et al. (2005), que trabalhando com Drimys brasiliensis Miers., verificaram que os maiores valores de velocidade e porcentagem de germinação são obtidos na temperatura constante de $17^{\circ} \mathrm{C}$. Barbosa et al. (2005) verificaram que a maior porcentagem de germinação e melhor expressão de vigor das sementes de Strelitzia reginae Ait foram obtidas a $25^{\circ} \mathrm{C}$.

Segundo Abreu \& Garcia (2005), as sementes de $X$. cipoensis Smith \& Downs, apresentaram maior porcentagem de germinação a $20^{\circ} \mathrm{C}$, ocorrendo uma redução significativa nas temperaturas de 25 e $30^{\circ} \mathrm{C}$ constantes e $20-30^{\circ} \mathrm{C}$ alternada. Verificaram ainda, que não ocorreu germinação nas temperaturas constantes de 35 e $40^{\circ} \mathrm{C}$ e nas alternâncias em que foi incluída a temperatura de $35^{\circ} \mathrm{C}$. Entretanto, diferindo da tanchagem, a germinabilidade foi menor a $15-25^{\circ} \mathrm{C}$ e nula a $15^{\circ} \mathrm{C}$.

\section{Efeito do substrato}

Valores relativos à porcentagem total de emergência estão apresentados na Figura 2A. A maior porcentagem de emergência ocorreu na areia, na mistura terra:vermiculita e terra:areia. Em seguida solo e vermiculita proporcionaram grande emergência, sendo que a menor foi observada em Plantmax $^{\circledR}$ e solo: Plantmax ${ }^{\circledR}$.

Quanto ao IVG (Figura 2B) o maior valor foi observado na areia e solo:vermiculita, seguido do solo e solo:areia, vermiculita e terra:Plantmax. O menor IVG ocorreu no Plantmax.
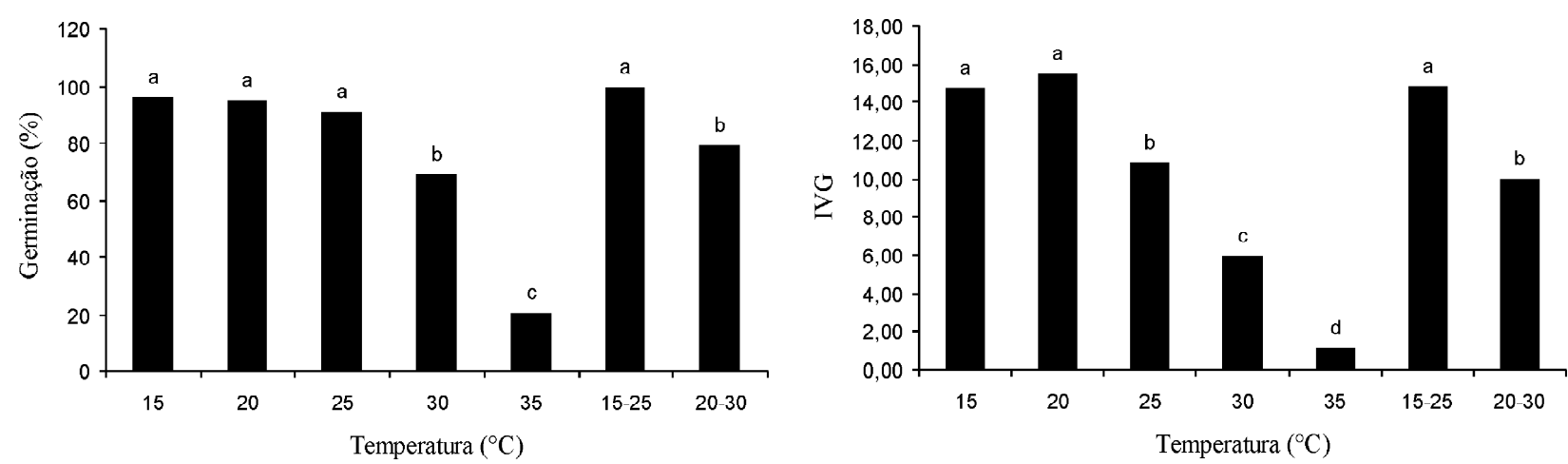

Figura 1 - Teste de germinação de sementes de tanchagem submetidas a diferentes temperaturas. A- Porcentagem germinação. B- Índice de velocidade de germinação. Médias seguidas da mesma letra não diferem entre si pelo teste de Tukey $(\mathrm{p} \leq 0,05)$. 

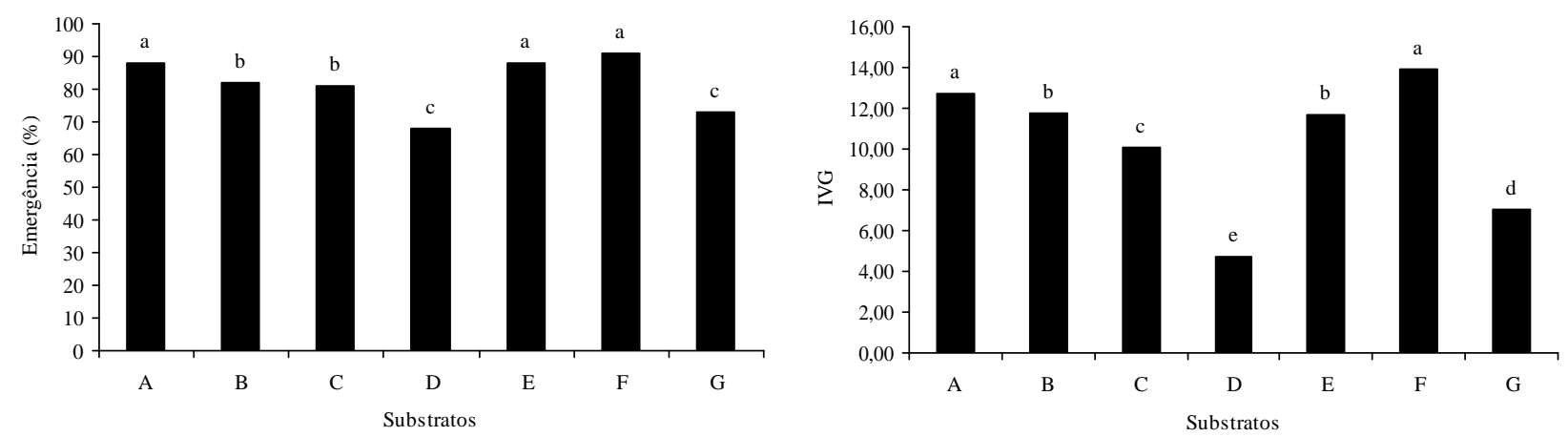

Figura 2 - Teste de emergência em diferentes substratos (A- areia; B- terra de subsolo; C- vermiculita; D- Plantmax ${ }^{\circledR}$; Esolo:areia; F- solo:vermiculita; G- solo: Plantmax ${ }^{\circledR}$ ). A- Porcentagem total de emergência. B- Índice de velocidade de emergência. Médias seguidas da mesma letra não diferem entre si pelo teste de Tukey $(\mathrm{p} \leq 0,05)$.

A vermiculita é um substrato que possui boa retenção de umidade, alta porosidade e baixa densidade, o que muitas vezes, proporciona maior facilidade para a plântula emergir. Tem sido usado com sucesso para espécies que possuem sementes de forma esférica, pois permite um maior contato com o substrato (VARELA et al., 2005). Entretanto, para a tanchagem, embora a semeadura tenha sido efetuada na superfície, ocorreu enterrio da semente durante o período de irrigação, devido a maior leveza deste substrato em relação aos demais.

A tanchagem apresenta sementes pequenas, achatadas e fotoblásticas positivas, sendo capazes de germinar apenas nas camadas superficiais do solo, onde são expostas à luz, que é necessária para a quebra da fotodormência. Espécies com sementes pequenas geralmente requerem luz para a germinação, o que resulta no impedimento do processo germinativo em profundidade no solo. Nesses casos a plântula apresenta dificuldade de emergir quando enterrada em conseqüência das reservas limitadas, que seriam esgotadas antes que a plântula alcance a superfície do solo e inicie o processo fotossintético (PEARSON et al., 2003).

Quando se utiliza terra em mistura com a vermiculita, não ocorre o enterrio das sementes, consistindo, juntamente com a areia, nos melhores substratos para emergência de plântulas de tanchagem. Como o substrato areia é mais barato e de fácil aquisição, em relação a vermiculita, é o substrato recomendado para emergência da tanchagem. A areia apresenta ainda a vantagem de poder ser reutilizada, desde que lavada e autoclavada (BRASIL, 1992). Resultados semelhantes foram encontrados por Abreu et al. (2005) e Lopes \& Pereira (2005), trabalhando respectivamente com sementes de Solanum sessiliflorum Dunal e Drimys brasiliensis Miers, que verificaram também, maior porcentagem de germinação das semeadas nos substratos areia, em relação a vermiculita.

Os maiores percentuais de emergência e de IVE obtidos na areia se deram, provavelmente, por ele reunir características físicas como porosidade e, ainda ser inócuo, características essas necessárias a um bom substrato para germinação. Uma boa porosidade permite o movimento de água e ar no substrato, favorecendo a germinação. Nessa fase, as sementes não necessitam de nutrientes, apenas que sejam hidratadas e aeradas para que ocorram as reações indutoras da formação do caulículo e radícula.

A esterilidade do substrato seria outro fator importante para o aumento na taxa de germinação das sementes, fato que não ocorre com o solo, fonte de patógenos, que poderiam afetar a germinação e o estabelecimento das plântulas (SIMÃO, 1971). Entretanto, a areia apresenta o inconveniente de drenar excessivamente a água, ficando a superfície ressecada, o que pode ser evitado através de regas diárias.

Já o Plantmax ${ }^{\circledR}$, embora apresente também boas características físicas proporcionou a menor germinação, provavelmente devido a compostos inibidores de germinação presentes na turfa. Por outro lado, a terra de subsolo apresenta baixa porosidade e elevada compactação devido ao teor de argila, além de maior possibilidade de contaminações.

\section{CONCLUSÃO}

As temperaturas constantes de 15 e $20^{\circ} \mathrm{C}$ e alternada de $15-25^{\circ} \mathrm{C}$, promoveram maiores porcentagens de 
germinação e IVG, sendo indicadas para testes de germinação em sementes de tanchagem. A areia é o substrato recomendado para emergência de plântulas, devido à elevada emergência e IVE encontrados.

\section{REFERÊNCIAS BIBLIOGRÁFICAS}

ABREU, D. C. A.; NOGUEIRA, A. C.; MEDEIROS, A. C. S. Efeito do substrato e da temperatura na germinação de sementes de cataia (Drimys brasiliensis Miers. Winteraceae). Revista Brasileira de Sementes, Pelotas, v. 27, n. 1, p. 149-157, 2005.

ABREU, M. E. P.; GARCIA, Q. S. Efeito da luz e da temperatura na germinação de sementes de quatro espécies de Xyris L. (Xyridaceae) ocorrentes na Serra do Cipó, MG, Brasil. Acta Botanica Brasilica, São Paulo, v. 19, n. 1, p. 149-154, jan./mar. 2005.

ACOSTA-PERCÁSTEGUI, J.; RODRÍGUEZ-TREJO, D. A. Factors affecting germination and pregerminative treatments of Lupinus montanus seeds. INCI, Caracas, v. 30, n. 9, p. 123-137, 2005.

BABBAR, S. B.; JAIN, N. 'Isubgol' as an alternative gelling agent in plant tissue culture media. Plant Cell Reports, [S.I.], v. 17, p. 318-322, 1998.

BARBOSA, J. G.; ALVARENGA, E. M.; DIAS, D. C. F. S.; VIEIRA, A. N. Efeito da escarificação ácida e de diferentes temperaturas na qualidade fisiológica de sementes de Strelitzia reginae. Revista Brasileira de Sementes, Brasília, v. 27, n. 1, p. 71-77, jun. 2005.

BARTLETT, M. S. The square root transformation in analysis of variance. Journal of the Royal Statistical Society, [S.I.], v. 3, p. 68-78, 1936. Supplement.

BEWLEY, J. D.; BLACK, M. Seeds: physiology of development and germination. 2. ed. New York: Plenum, 1994. $445 \mathrm{p}$.

BRASIL. Ministério da Agricultura e Reforma Agrária. Regras para análise de sementes. Brasília, DF, 1992. 365 p.

CARVALHO, N. M.; NAKAGAWA, J. Sementes: ciência, tecnologia e produção. 4. ed. Jaboticabal: Funep, 2000. $588 \mathrm{p}$.
DUARTE, M. G. R.; SOARES, I. A. A.; BRANDÃO, M.; JÁCOME, R. L. R. P.; FERREIRA, M. D.; SILVA, C. R. F.; OLIVEIRA, A. B. Perfil fitoquímico e atividade antibacteriana in vitro de plantas invasoras. Revista Lecta, Bragança Paulista, v. 20, n. 2, p. 177-182, jul./dez. 2002.

FERREIRA, D. F. SISVAR 4. 3- Sistema de analises estatísticas. Lavras: UFLA, 1999.

FIGLIOLIA, M. B.; OLIVEIRA, E. C.; PIÑA-RODRIGUES, F. C. M. Análise de sementes. In: AGUIAR, I. B.; PIÑARODRIGUES, F. C. M. (Coords.). Sementes florestais tropicais. Brasília, DF: Abrates, 1993. p. 137-174.

HARTWELL, J. L. Plants used against cancer: a survey. Lawrence: Quarterman, 1982.

KISSMANN, K. G.; GROTH, D. Plantas infestantes e nocivas. 2. ed. São Paulo: BASF, 2000. 726 p.

KOLLER, O. Environmental control of seed germination. London: Academic, 1972.

LOPES, J. C.; PEREIRA, M. D. Germinação de sementes de cubiu em diferentes substratos e temperaturas. Revista Brasileira de Sementes, Pelotas, v. 27, n. 2, p. 146-150, Dec. 2005.

MAGUIRE, J. D. Speed of germination-aid in selection and evaluation for seedling emergence and vigour. Crop Science, Madson, v. 2, n. 1, p. 176-177, Jan./Feb. 1962.

MARTINS, E. R.; CASTRO, D. M.; CASTELLANI, D. C.; DIAS, J. E. Plantas medicinais. Viçosa: UFV, 2000. 220 p.

OLIVEIRA, L. M.; CARVALHO, M. L. M.; SILVA, T. T. A.; BORGES, D. I. Temperatura e regime de luz na germinação de sementes de Tabebuia impetiginosa (Martius ex A. P. de Candolle) Standley e T. serratifolia Vahl Nich. Bignoniaceae. Ciência e Agrotecnologia, Lavras, v. 29, n. 3, p. 642-648, maio/jun. 2005.

OLIVEIRA, P. G.; GARCIA, Q. S. Efeitos da luz e da temperatura na germinação de sementes de Syngonanthus elegantulus Ruhland, S. elegans (Bong.) Ruhland e $S$. venustus Silveira (Eriocaulaceae). Acta Botânica Brasílica, Porto Alegre, v. 19, n. 3, p. 639-645, 2005. 
PEARSON, T. R. H.; BURSLEM, D. F. R. P.; MULLINS, C. E.; DALLING, J. W. Functional significance of photoblastic germination in neotropical pioneer trees: a seed's eye view. Functional Ecology, [S.1.], v. 17, p. 394-402, 2003.

POPININGIS, F. Fisiologia de sementes. Brasília, DF: Agriplan, 1985. 285 p.

SIMÃO, S. Manual de fruticultura. São Paulo: Ceres, 1971. $530 \mathrm{p}$.

THOMPSON, P. A. Characterization of the germination response to temperature of species and ecotypes. Nature, London, v. 225, p. 827-831, 1970.
TUKEY, J. W. One degree of freedom for non-additivity. Biometrics, Washington, v. 5, p. 232-242, 1949.

UPNMOOR, I. Cultivo de plantas medicinais, aromáticas e condimentares. Guaíba: Agropecuária, 2003. 56 p.

VARELA, V. P.; COSTA, S. S.; RAMOS, M. B. P. Influência da temperatura e do substrato na germinação de sementes de itaubarana (Acosmium nitens (Vog.) Yakovlev) Leguminosae, Caesalpinoideae. Acta Amazônica, Manaus, v. 35, n. 1, p. 35-39, 2005.

ZAR, J. H. Biostatistical analysis. 4. ed. New York: Prentice Hall, 1999. 929 p. 